\title{
Higher Cystatin C Level Increase the Risk of Delayed Cerebral Ischemia after Endovascular Treatment of Aneurysmal Subarachnoid Hemorrhage: A Case- Control Study.
}

\section{Kehua Chen}

the First Affiliated Hospital of Shantou University Medical College

Guanghua Huang

Shantou University Medical College

Chengwei Cai

the First Affiliated Hospital of Shantou University Medical College

Chuangnan Yan

the First Affiliated Hospital of Shantou University Medical College

Fuguang Zhang

the First Affiliated Hospital of Shantou University Medical College

Min Yao

Shenzhen University

Junqiang Ma

the First Affiliated Hospital of Shantou University Medical College

Hongwu Xu ( $\nabla$ hwxu@qq.com )

First Hospital of Medical College of Shantou University https://orcid.org/0000-0002-5857-3384

\section{Research Article}

Keywords: Cystatin C, delayed cerebral ischemia, endovascular treatment, aneurysmal subarachnoid hemorrhage

Posted Date: December 13th, 2021

DOI: https://doi.org/10.21203/rs.3.rs-1145312/v1

License: (1) This work is licensed under a Creative Commons Attribution 4.0 International License. Read Full License 


\section{Abstract}

Cystatin $\mathrm{C}$ (CysC) has been found to be associated with hemorrhagic and ischemic stroke in many studies. However, the association between CysC level and the risk of delayed cerebral ischemia after endovascular treatment of aneurysmal subarachnoid hemorrhage has been reported rarely. Our study was proposed to explore this association. Consecutive patients from June 2015 to February 2021 in this single-center retrospective study were selected. Univariate and multivariate analyses were used to identify potential prognostic risk factors for delayed cerebral ischemia, and the stability of the association was demonstrated by several statistical methods, such as subgroup analysis, interaction testing, generalized linear models, and propensity score matching. A total of 424 patients were included in the analysis. Cystatin C was independently associated with delayed cerebral ischemia. The independent effects of CysC on delayed cerebral ischemia were shown in generalized linear models with a logit link, and the results were relatively stable in crude, partial, and full models with ORs $(95 \% \mathrm{Cls})$ for delayed cerebral ischemia. Subgroup analysis showed no significant subgroup differences in the effect of CysC on delayed cerebral ischemia. There was also no interaction effect between CysC and other confounders. Patients in the high CysC group had a higher risk of delayed cerebral ischemia than those in the low CysC group before and after propensity score matching. CysC level could be an independent predictor for the risk of delayed cerebral ischemia after endovascular treatment of aneurysmal subarachnoid hemorrhage.

\section{Introduction}

Spontaneous subarachnoid hemorrhage (SAH) causes $1-6 \%$ of strokes [7]. Approximately $30 \%$ of SAH patients experience delayed cerebral ischemia (DCl), which usually occurs between 4 and 10 days after $\mathrm{SAH}[4,22]$. Patients who suffered from $\mathrm{DCl}$ are generally associated with poor functional outcome [17]. Ruptured intracranial aneurysms cause nearly $85 \%$ of SAH [25], and endovascular treatment has gradually become the preferred option for ruptured intracranial aneurysms whenever feasible [28].

Chronic kidney disease has been gradually recognized as an independent risk factor for the occurrence of cerebrovascular disease [11]. Cystatin C (CysC), as a low molecular weight inhibitor of cysteine proteases, is produced and released constantly from all nucleated cells. Compared with serum creatinine level or glomerular filtration rate, $\mathrm{CysC}$ is considered to be a more sensitive parameter for assessing renal function $[11,13]$.

CysC has been found to be associated with hemorrhagic and ischemic stroke in many studies. Research has focused on the difference of subtypes of cerebral infarction, the volume of cerebral hemorrhage, and the extent and the prognosis of cerebral infarction $[3,19,27,30]$. Recently, a prospective and multicenter nested case-control study suggests that patients in the poor functional outcome group (mRS 3-5) present higher CysC level on admission than those in the good functional outcome group (mRS 0-2) at 90 days of follow-up after stroke onset [1]. However, the association between CysC level and risk of DCl after endovascular treatment of aneurysmal subarachnoid hemorrhage (aSAH) has been reported rarely as we 
know. The purpose of this study was to explore the association between the first CysC level within $48 \mathrm{~h}$ after admission and the risk of $\mathrm{DCl}$ in patients with aSAH following endovascular treatment.

\section{Materials And Methods}

\section{Patients}

After approval from the institutional review board, informed consent was waived in this retrospective study. Consecutive patients from June 2015 to February 2021 in the First Affiliated Hospital of Shantou University Medical College were selected. The inclusion criteria for this retrospective study were as follows: (1) aSAH with available brain non-contrast computed tomography taken at admission, and confirmation of ruptured aneurysm by computed tomography angiography, magnetic resonance angiography, or digital subtraction angiography; (2) age $\geqq 18$ years; (3) length of hospitalization $\geqq 3$ days; (4) patients had received endovascular coiling or surgical clipping during hospitalization.

Exclusion criteria were as follows: (1) history of cranial surgery; (2) history of cerebral infarction or intracerebral hemorrhage; (3) patients underwent surgical clipping treatment during hospitalization; (4) non-aneurysm-related therapeutic surgery was performed during hospitalization; (5) the time from onset to endovascular coiling exceeded 3 days; (6) patients with missing data.

\section{Definition Of Dci}

DCl was diagnosed as clinical deterioration, a new infarction on cerebral CT or MRI scanning, or both. Clinical deterioration caused by DCl was defined as: a) new focal neurological impairment (such as hemiparesis, hemianopia, aphasia, apraxia, or neglect, and b) a decrease of at least 2 points on the Glasgow Coma Scale (GCS). Clinical deterioration had to last for at least 1 hour, was not apparent immediately after accepting aneurysm occlusion, nor be attributed to other causes based on comprehensive assessment (such as relevant laboratory results, CT or MRI scanning of the brain, and clinical assessment). A new infarction on brain CT or MRI was not present on admission or between 24 and 48 hours after accepting aneurysm occlusion. Both clinical deterioration and new infarction were assessed by the same two authors independently during hospitalization $[8,26]$.

\section{Data Collection}

Data were recorded as follows: age, gender, and admission status at admission (World Federation of Neurosurgical Societies (WFNS) grade, Hunt-Hess grade). Baseline biological results should be obtained within the first $48 \mathrm{~h}$ after admission (serum CysC, albumin, white blood cell (WBC) count, neutrophil-tolymphocyte ratio (NLR)). Radiological examinations should be the first within $48 \mathrm{~h}$ after admission (modified Fisher (mFisher) grade, intracerebral hemorrhage (ICH), intraventricular hemorrhage (IVH), hydrocephalus, aneurysm size, aneurysm location). For statistical analysis of subgroups, multi- 
categorical variables and continuity variables were grouped based on previous literature and clinical significance as follows: WFNS grade (grade I-III and grade IV-V), mFisher grade (grade I-II and grade III-IV), Hunt \& Hess grade (grade I-III and grade IV-V), aneurysm location (group 1: posterior circulation (PC), group 2: anterior communicating artery and anterior cerebral artery (ACA+ACOA), group 3: internal carotid artery (ICA), group 4: middle cerebral artery (MCA)), age ( $\leqq 55 \mathrm{y},>55 \mathrm{y})$, Alb ( $\leqq 40 \mathrm{~g} / \mathrm{L},>40 \mathrm{~g} / \mathrm{L})$, aneurysm size $(\leqq 5 \mathrm{~mm},>5 \mathrm{~mm})$, length of hospitalization ( $\leqq 28 \mathrm{~d},>28 \mathrm{~d})$.

\section{Statistical Analysis}

Categorical variables were represented with counts (proportions) in each subgroup. After being assessed for normality in continuous variables, normally distributed variables were presented with mean $\pm S D$. Nonparametric variables were presented with median (IQR). Statistical analysis of baseline characteristics and clinical data were compared between the non- $\mathrm{DCl}$ group and $\mathrm{DCl}$ group. The Student ttest or paired t-test was used to compare continuous normally distributed variables, and the MannWhitney U-test or Wilcoxon rank-sum test was used to compare nonparametric variables. The $\chi^{2}$ test, McNemar's test or McNemar-Bowker's test was used to compare dichotomous and multi-categorical variables.

The multivariate logistic regression model included all variables with statistical significance ( $p$ values < 0.05 ) in the univariate analysis and clinically important variables. Adjusted smooth curve fitting and generalized linear models with a logit link were used to show the independent effects of CysC on DCI with crude, partial, and full models. The forest plot presented the subgroup analysis in $\mathrm{DCl}$ and the interaction test between CysC and other confounders.

The receiver operating characteristic (ROC) analysis was applied to investigate the effects of CysC on DCl and identify the best cutoff value for $\mathrm{DCl}$. Subsequently, all included patients were dichotomized by the identified cutoff CysC value. Propensity score matching was undertaken to minimize unbalanced confounding between the high CysC and low CysC groups. Groups were matched in a 1:1 ratio and with a 0.03 caliper. Subjects were matched as follows: age, gender, WFNS grade, Hunt-Hess grade, WBC, NLR, albumin, mFisher grade, ICH, IVH, hydrocephalus, aneurysm size, aneurysm location, and length of hospitalization.

Most statistical analyses were performed using EmpowerStats software 2.0 (http://www.empowerstats.com/cn/) and R-project (version 3.4.3). Propensity score matching and normality testing were calculated by SPSS 22.0 (SPSS Institute). P-values $<0.05$ were considered statistically significant.

\section{Results}

In total, 671 patients satisfied the inclusion criteria. After screening strictly based on the exclusion criteria, 247 patients were excluded (history of cranial surgery, $n=17$; history of cerebral infarction or intracerebral 
hemorrhage, $n=10$; surgical clipping, $n=36$; Non-aneurysm related therapeutic surgery, $n=4$; time from onset to endovascular coiling $>3$ days, $n=139$; missing data, $n=41$ ). Finally, 424 patients fulfilled the inclusion criteria and were not excluded by the exclusion criteria. Among included patients, 138 (32.55\%) patients developed DCl. Baseline clinical characteristics of included patients are shown in Table 1.

Comparison of baseline clinical characteristics between the non- $\mathrm{DCl}$ group and $\mathrm{DCl}$ group revealed no

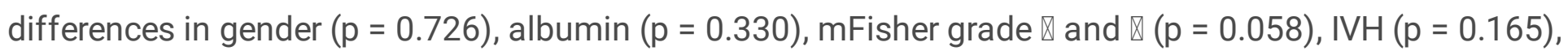
hydrocephalus $(p=0.263)$, aneurysm size $(p=0.740)$, and aneurysm location $(p=0.051)$. The following variables, however, showed significant differences: age $(p=0.022)$, WFNS grade $\otimes$ and $\otimes(p=0.003)$, HuntHess grade $\nabla$ and $\otimes(p=0.004)$, WBC count $(p=0.028)$, CysC $(p=0.007), \mathrm{ICH}(p=0.008)$, length of hospitalization $(p<0.001)$. 
Table 1

Baseline clinical characteristics.

\begin{tabular}{|c|c|c|c|}
\hline Variable & Non-DCl $(n=286)$ & $\mathrm{DCl}(\mathrm{n}=138)$ & P-value \\
\hline Age, median (IQR), y & $58.00(49.25-65.00)$ & $61.00(52.00-67.00)$ & 0.022 \\
\hline Gender, male, No. (\%) & $117(40.91 \%)$ & $54(39.13 \%)$ & 0.726 \\
\hline WFNS grade $\triangle$ and $\triangle$, No. (\%) & $85(29.72 \%)$ & $61(44.20 \%)$ & 0.003 \\
\hline Hunt - Hess grade $\otimes$ and $\otimes$, No. (\%) & $144(50.35 \%)$ & $90(65.22 \%)$ & 0.004 \\
\hline WBC, median (IQR), 109/I & $13.45(10.54-17.01)$ & $14.49(11.49-17.98)$ & 0.028 \\
\hline NLR, median (IQR) & $9.30(5.06-13.96)$ & $9.13(5.37-15.96)$ & 0.668 \\
\hline CysC, median (IQR), mg/l & $0.70(0.58-0.87)$ & $0.74(0.64-0.97)$ & 0.007 \\
\hline Albumin, mean $\pm S D, g / l$ & $38.68 \pm 4.10$ & $38.23 \pm 4.96$ & 0.330 \\
\hline 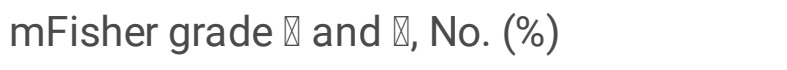 & $215(75.17 \%)$ & $115(83.33 \%)$ & 0.058 \\
\hline $\mathrm{ICH}$, No. (\%) & $49(17.13 \%)$ & $39(28.26 \%)$ & 0.008 \\
\hline IVH, No. (\%) & $175(61.19 \%)$ & $94(68.12 \%)$ & 0.165 \\
\hline Hydrocephalus, No. (\%) & $81(28.32 \%)$ & $32(23.19 \%)$ & 0.263 \\
\hline Aneurysm size, median (IQR), mm & $5.00(3.60-6.50)$ & $4.80(3.60-6.88)$ & 0.740 \\
\hline Aneurysm location, No. (\%) & & & 0.051 \\
\hline PCA & $20(6.99 \%)$ & $5(3.62 \%)$ & \\
\hline $\mathrm{ACA}+\mathrm{ACOA}$ & $117(40.91 \%)$ & $46(33.33 \%)$ & \\
\hline ICA & $79(27.62 \%)$ & $37(26.81 \%)$ & \\
\hline MCA & $70(24.48 \%)$ & $50(36.23 \%)$ & \\
\hline length of hospitalization, median (IQR), d & $20.00(14.00-29.00)$ & $28.50(16.00-41.00)$ & $<0.001$ \\
\hline \multicolumn{4}{|c|}{$\begin{array}{l}\text { Notes: Continuous variables are shown as mean } \pm \text { SD or median (IQR), categorical variables are } \\
\text { shown as No. (\%). }\end{array}$} \\
\hline \multicolumn{4}{|c|}{$\begin{array}{l}\text { Abbreviations: DCI, delayed cerebral ischemia; IQR: interquartile range; SD, standard deviation; WFNS, } \\
\text { World Federation of Neurosurgical Societies; WBC, white blood cell count; NLR, neutrophil-to- } \\
\text { lymphocyte ratio; CysC, cystatin C; mFisher Scale, modified Fisher scale; ICH, intracerebral } \\
\text { hemorrhage; IVH, intraventricular hemorrhage; PC, posterior circulation; ACOA, anterior communicating } \\
\text { artery; ACA, anterior cerebral artery; ICA, internal carotid artery; MCA, middle cerebral artery. }\end{array}$} \\
\hline
\end{tabular}

The multivariate logistic regression model included all variables with statistical significance ( $p$ values < $0.05)$ in the univariate analysis and clinically important variables, such as mFishers grade and aneurysm location. The results are presented in Table 2. CysC was independently associated with the occurrence of $\mathrm{DCl}(\mathrm{OR} 2.3,95 \% \mathrm{Cl} 1.06-5.02, \mathrm{p}=0.036)$. 
Table 2

Multivariate logistic regression analysis of delayed cerebral ischemia prediction.

\begin{tabular}{|c|c|c|c|}
\hline Variable & Odds Ratio & $95 \% \mathrm{Cl}$ & P-value \\
\hline Age & 1.01 & $(0.99,1.03)$ & 0.464 \\
\hline WFNS grade $\nabla$ and $\otimes$ & 1.2 & $(0.70,2.08)$ & 0.507 \\
\hline WBC & 1.03 & $(0.98,1.07)$ & 0.285 \\
\hline Hunt - Hess grade $\otimes$ and & 1.32 & $(0.79,2.20)$ & 0.297 \\
\hline CysC & 2.3 & $(1.06,5.02)$ & 0.036 \\
\hline 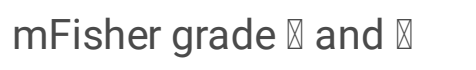 & 1.46 & $(0.84,2.55)$ & 0.177 \\
\hline $\mathrm{ICH}$ & 1.3 & $(0.75,2.25)$ & 0.351 \\
\hline \multicolumn{4}{|l|}{ Aneurysm location } \\
\hline PCA & 1 & & \\
\hline $\mathrm{ACA}+\mathrm{ACOA}$ & 1.32 & $(0.46,3.82)$ & 0.609 \\
\hline ICA & 2.05 & $(0.69,6.05)$ & 0.195 \\
\hline MCA & 2.72 & $(0.93,7.98)$ & 0.068 \\
\hline length of hospitalization & 1.01 & $(1.00,1.01)$ & 0.221 \\
\hline
\end{tabular}

This study focuses on demonstrating the association between CysC and the occurrence of $\mathrm{DCl}$. As is shown in Figure 1, the linear correlation between CysC and the probability of $\mathrm{DCl}$ is presented using adjusted smooth curve fitting $(p=0.033)$. The independent effects of CysC and $\mathrm{DCl}$ were shown in generalized linear models with a logit link, and the results were relatively stable in crude, partial adjustment models and full models with ORs (95\% Cls) for DCl of $2.83(1.40,5.72), 2.56(1.21,5.42)$, and $2.42(1.07,5.44)$, respectively (Table 3$)$. Given the small range of values and clinical applicability, the CysC. 1 (CysC increase per 0.1 change) and CysC Z score (CysC increase per SD change) were used to represent the $\mathrm{OR}$ between $\mathrm{CysC}$ and $\mathrm{DCl}$. After being adjusted by full models, the CysC. 1 and CysC Z scores presented both significant differences with ORs $(95 \% \mathrm{Cls})$ for $\mathrm{DCl}$ of $1.09(1.01,1.18)$ and 1.29 $(1.02,1.63)$, respectively. 
Table 3

Association between CysC level and the occurrence risk of DCl.

\begin{tabular}{|c|c|c|c|}
\hline \multirow[t]{2}{*}{ Variable } & \multicolumn{3}{|c|}{ Odds Ratio (95\% Cl) P-value } \\
\hline & Non-adjusted & Adjust I & Adjust II \\
\hline CysC & $2.83(1.40,5.72) 0.004$ & $2.56(1.21,5.42) 0.014$ & $2.42(1.07,5.44) 0.033$ \\
\hline CysC Z score* & $1.35(1.10,1.66) 0.004$ & $1.31(1.06,1.63) 0.014$ & $1.29(1.02,1.63) 0.033$ \\
\hline CysC1† & $1.11(1.03,1.19) 0.004$ & $1.10(1.02,1.18) 0.014$ & $1.09(1.01,1.18) 0.033$ \\
\hline \multicolumn{4}{|c|}{ Non-adjusted model: None; } \\
\hline \multicolumn{4}{|c|}{ Adjusted model l: age, gender; } \\
\hline \multicolumn{4}{|c|}{$\begin{array}{l}\text { Adjusted model II: age, gender, WFNS grade, Hunt \& Hess grade, WBC count, NLR, albumin, mFisher } \\
\text { grade, ICH, IVH, hydrocephalus, aneurysm size, aneurysm location, length of hospitalization. }\end{array}$} \\
\hline \multicolumn{4}{|c|}{ *: CysC increase per SD change. } \\
\hline \multicolumn{4}{|c|}{ †: CysC increase per 0.1 change. } \\
\hline
\end{tabular}

The results were shown as a forest plot to better describe the subgroup differences and the interactions between CysC and other confounders on $\mathrm{DCl}$ (Figure 2). However, subgroup analysis indicated that there were no significant subgroup differences in $\mathrm{DCl}$. There were also no interaction effects between CysC and other confounders. After ROC analysis, a CysC level of $0.595 \mathrm{mg} / \mathrm{l}$ was identified as the best cutoff threshold to discriminate the occurrence of $\mathrm{DCl}(\mathrm{AUC}(95 \% \mathrm{Cl}) 0.584(0.532-0.639)$, Specificity $=0.301$, Sensitivity $=0.862$, Youden's index $=0.163)($ Figure 3$)$.

The patients were divided into two groups based on their $\mathrm{CysC}$ level at the time of admission: low group(CysC $\leqq 0.59 \mathrm{mg} / \mathrm{l}$ ) and high group(CysC $>0.59 \mathrm{mg} / \mathrm{l})$. Patients in the high CysC group had a higher risk of $\mathrm{DCl}$ in the unadjusted analysis $(37.30 \%$ vs $18.10 \%, \mathrm{p}<0.001)$. Propensity score matching (PSM) was performed to minimize bias by confounding between patients with CysC level $\leqq 0.59 \mathrm{mg} / \mathrm{l}$ versus > $0.59 \mathrm{mg} / \mathrm{l}$. After PSM, two relatively balanced cohorts ( $\mathrm{n}=83$ in each group, Table 4) were available to analyze the relationship between $\mathrm{CysC}$ and $\mathrm{DCl}$. In the high CysC group, patients also presented a higher risk for $\mathrm{DCl}$ than those in the low CysC group (37.35\% vs $19.28 \%, \mathrm{p}=0.020)$. 
Table 4

Clinical characteristics of patients who were divided into the high and low level of CysC before and after propensity score matching (PSM).

\begin{tabular}{|c|c|c|c|c|c|c|}
\hline & \multicolumn{3}{|l|}{ Before PSM } & \multicolumn{3}{|l|}{ After PSM } \\
\hline & $\begin{array}{l}\text { CysC } \\
\leqq 0.59 \mathrm{mg} / \mathrm{l} \\
(\mathrm{n}=105)\end{array}$ & $\begin{array}{l}\text { CysC > } 0.59 \\
\mathrm{mg} / \mathrm{l} \\
(\mathrm{n}=319)\end{array}$ & $\begin{array}{l}\mathrm{P} \text { - } \\
\text { value }\end{array}$ & $\begin{array}{l}\text { CysC } \\
\leqq 0.59 \mathrm{mg} / \mathrm{l} \\
(\mathrm{n}=83)\end{array}$ & $\begin{array}{l}\text { CysC > } \\
0.59 \mathrm{mg} / \mathrm{l} \\
(\mathrm{n}=83)\end{array}$ & $\begin{array}{l}\mathrm{P} \text { - } \\
\text { value }\end{array}$ \\
\hline $\begin{array}{l}\text { Age, median (IQR)/ } \\
\text { mean } \pm S D, y\end{array}$ & $\begin{array}{l}51.00 \\
(46.00- \\
60.00)\end{array}$ & $\begin{array}{l}61.00 \\
(52.00- \\
66.50)\end{array}$ & $<0.001$ & $\begin{array}{l}54.10 \pm \\
9.22\end{array}$ & $\begin{array}{l}53.81 \pm \\
11.19\end{array}$ & 0.832 \\
\hline $\begin{array}{l}\text { length of } \\
\text { hospitalization, } \\
\text { median (IQR), d }\end{array}$ & $\begin{array}{l}19.00 \\
(13.00- \\
28.00)\end{array}$ & $\begin{array}{l}22.00 \\
(16.00- \\
35.00)\end{array}$ & 0.005 & $\begin{array}{l}20.00 \\
(13.00- \\
30.00)\end{array}$ & $\begin{array}{l}18.00 \\
(12.50- \\
27.50)\end{array}$ & 0.606 \\
\hline $\begin{array}{l}\text { WBC, median (IQR), } \\
10^{9} / \mathrm{I}\end{array}$ & $\begin{array}{l}13.48 \\
(10.08- \\
17.06)\end{array}$ & $\begin{array}{l}14.10 \\
(10.86- \\
17.28)\end{array}$ & 0.379 & $\begin{array}{l}13.67 \\
(10.47- \\
17.29)\end{array}$ & $\begin{array}{l}13.18 \\
(10.95- \\
16.69)\end{array}$ & 0.863 \\
\hline NLR, median (IQR) & $\begin{array}{l}7.67(3.13- \\
13.53)\end{array}$ & $\begin{array}{l}9.50(5.73- \\
14.49)\end{array}$ & 0.063 & $\begin{array}{l}8.00(3.50- \\
14.50)\end{array}$ & $\begin{array}{l}9.00(6.00- \\
12.00)\end{array}$ & 0.788 \\
\hline $\begin{array}{l}\text { Albumin, mean } \pm S D \text {, } \\
\mathrm{g} / \mathrm{l}\end{array}$ & $39.96 \pm 4.20$ & $38.06 \pm 4.37$ & $<0.001$ & $\begin{array}{l}39.89 \pm \\
4.25\end{array}$ & $\begin{array}{l}40.02 \pm \\
4.04\end{array}$ & 0.816 \\
\hline $\begin{array}{l}\text { Aneurysm size, } \\
\text { median (IQR), mm }\end{array}$ & $\begin{array}{l}4.60(3.50- \\
6.20)\end{array}$ & $\begin{array}{l}4.90(3.60- \\
6.65)\end{array}$ & 0.558 & $\begin{array}{l}5.00(3.60- \\
6.65)\end{array}$ & $\begin{array}{l}5.00(4.00- \\
6.35)\end{array}$ & 0.722 \\
\hline $\begin{array}{l}\text { Gender, male, No. } \\
(\%)\end{array}$ & $28(26.67 \%)$ & $\begin{array}{l}143 \\
(44.83 \%)\end{array}$ & 0.001 & $\begin{array}{l}25 \\
(30.12 \%)\end{array}$ & $\begin{array}{l}31 \\
(37.35 \%)\end{array}$ & 0.392 \\
\hline $\begin{array}{l}\text { WFNS grade } \triangle \text { and } \otimes, \\
\text { No. }(\%)\end{array}$ & $28(26.67 \%)$ & $\begin{array}{l}118 \\
(36.99 \%)\end{array}$ & 0.053 & $\begin{array}{l}25 \\
(30.12 \%)\end{array}$ & $\begin{array}{l}26 \\
(31.33 \%)\end{array}$ & 0.644 \\
\hline $\begin{array}{l}\text { mFisher grade } \otimes \text { and } \\
\bigotimes, \text { No. (\%) }\end{array}$ & $68(64.76 \%)$ & $\begin{array}{l}262 \\
(82.13 \%)\end{array}$ & $<0.001$ & $\begin{array}{l}60 \\
(72.29 \%)\end{array}$ & $\begin{array}{l}55 \\
(66.27 \%)\end{array}$ & 0.500 \\
\hline $\mathrm{ICH}$, No. (\%) & $14(13.33 \%)$ & 74 (23.20\%) & 0.031 & $\begin{array}{l}14 \\
(16.87 \%)\end{array}$ & $\begin{array}{l}17 \\
(20.48 \%)\end{array}$ & 0.690 \\
\hline $\begin{array}{l}\text { Hydrocephalus, No. } \\
(\%)\end{array}$ & $26(24.76 \%)$ & $87(27.27 \%)$ & 0.614 & $\begin{array}{l}21 \\
(25.30 \%)\end{array}$ & $\begin{array}{l}18 \\
(21.69 \%)\end{array}$ & 0.690 \\
\hline IVH, No. (\%) & $67(63.81 \%)$ & $\begin{array}{l}202 \\
(63.32 \%)\end{array}$ & 0.928 & $\begin{array}{l}55 \\
(66.27 \%)\end{array}$ & $\begin{array}{l}56 \\
(67.47 \%)\end{array}$ & 1.000 \\
\hline 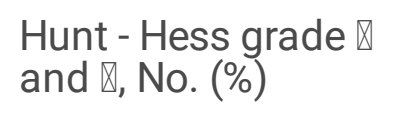 & $54(51.43 \%)$ & $\begin{array}{l}180 \\
(56.43 \%)\end{array}$ & 0.372 & $\begin{array}{l}45 \\
(54.22 \%)\end{array}$ & $\begin{array}{l}45 \\
(54.22 \%)\end{array}$ & 1.000 \\
\hline $\begin{array}{l}\text { Aneurysm location, } \\
\text { No. (\%) }\end{array}$ & & & 0.522 & & & 0.815 \\
\hline PCA & $8(7.62 \%)$ & $17(5.33 \%)$ & & $7(8.43 \%)$ & $5(6.02 \%)$ & \\
\hline
\end{tabular}




\begin{tabular}{|c|c|c|c|c|c|c|}
\hline & Before PSM & & & After PSM & & \\
\hline $\mathrm{ACA}+\mathrm{ACOA}$ & 37 (35.24\%) & $\begin{array}{l}126 \\
(39.50 \%)\end{array}$ & & $\begin{array}{l}29 \\
(34.94 \%)\end{array}$ & $\begin{array}{l}36 \\
(43.37 \%)\end{array}$ & \\
\hline ICA & 33 (31.43\%) & $83(26.02 \%)$ & & $\begin{array}{l}24 \\
(28.92 \%)\end{array}$ & $\begin{array}{l}21 \\
(25.30 \%)\end{array}$ & \\
\hline MCA & 27 (25.71\%) & $93(29.15 \%)$ & & $\begin{array}{l}23 \\
(27.71 \%)\end{array}$ & $\begin{array}{l}21 \\
(25.30 \%)\end{array}$ & \\
\hline DCl, No. (\%) & $19(18.10 \%)$ & $\begin{array}{l}119 \\
(37.30 \%)\end{array}$ & $<0.001$ & $\begin{array}{l}16 \\
(19.28 \%)\end{array}$ & $\begin{array}{l}31 \\
(37.35 \%)\end{array}$ & 0.020 \\
\hline
\end{tabular}

\section{Discussion}

This case-control study identified an association between CysC level and risk of $\mathrm{DCl}$ after endovascular treatment of aneurysmal subarachnoid hemorrhage. The incidence of $\mathrm{DCl}$ in our study (32.55\%) is similar to previous literature $[22,24]$. Several risk factors for DCI were identified in the univariate analysis, including WFNS grade, Hunt-Hess grade, WBC count, $\mathrm{CysC}, \mathrm{ICH}$, aneurysm location, and length of hospitalization. The association between DCI and other factors (such as WFNS grade, Hunt-Hess grade, WBC count, aneurysm location (MCA), ICH) have been reported $[2,6,18,21,29]$. In the multivariate logistic regression model, CysC showed an independent association with the occurrence of DCl. Our study demonstrates the stable association between CysC and DCl by several statistical methods. First, the test of interaction revealed no significant subgroup differences between CysC and other confounders on DCl. Secondly, the linear relationship of CysC level and the risk of $\mathrm{DCl}$ was confirmed after being calculated by generalized linear models with a logit link. Finally, ROC analysis was used to determine the best cutoff threshold for discriminating the occurrence of DCl; patients in the high CysC group (CysC >0.59 mg/l) had a higher risk of DCl than those in the low CysC group both before PSM and after PSM $(37.30 \%$ vs $18.10 \%, 37.35 \%$ vs $19.28 \%$, respectively).

Multivariate analysis showed CysC to be independently associated with $\mathrm{DCl}$. Differences in design from previous studies showed as follow. First, the occurrence of $\mathrm{DCl}$ is time-dependent, with $\mathrm{DCl}$ occurring most frequently between 4 and 10 days after SAH [4]. However, because the endpoint for DCl observation in most previous studies was at hospital discharge [12,14, 21], outcome bias caused by different observation times could not be ignored. In our study, the $\mathrm{DCl}$ group had longer hospitalizations (28.50 days [IQR 16.00-41.00] vs 20.00 days [IQR 14.00-29.00]). However, few previous studies had taken the length of hospitalization into consideration, which may lead to outcome reporting bias. Therefore, the length of hospitalization was taken into account in this study. Second, this study focused on exploring the relationship between CysC and DCl after endovascular treatment of aSAH, the effect of neurosurgical clipping for DCl was ignored. Last but not least, the time of intervention was different with some reported studies. The timeliness of receiving therapeutic intervention was considered a critical factor affecting clinical deterioration by DCl [5]. Delayed hospital admission (more than 48 hours after onset of symptoms) incurred a higher risk of DCl compared to early hospital admission (within 24 hours after 
onset) [9]. To reduce the impact of intervention time, this study excluded delayed intervention patients who had received endovascular coiling more than 3 days after onset.

This study identifies the independent association between CysC and $\mathrm{DCl}$, and suggests that a higher level of CysC may predict a higher risk of $\mathrm{DCl}$. A higher level of CysC was confirmed to be strongly associated with a higher occurrence risk of both ischemic and hemorrhagic stroke [19]. There was a study that also reported that the level of CysC in the large infarct size group ( $>4 \mathrm{~cm}$ in diameter on MRI) was higher than those in the small infarct size group $(1.100 \pm 0.270 \mathrm{mg} / \mathrm{l}$ vs $0.941 \pm 0.217 \mathrm{mg} / \mathrm{l}, \mathrm{p}=0.005)$. Similarly, the level of CysC was higher in the larger hemorrhage volume group (>30 ml) than the small hemorrhage volume group ( $\leqq 30 \mathrm{ml}(1.263 \pm 0.697 \mathrm{mg} / \mathrm{l}$ vs $0.957 \pm 0.260 \mathrm{mg} / \mathrm{l}, \mathrm{p}=0.006)$ [2]. A study of 40 microsurgically clipped aSAH patients reported that cerebrospinal fluid CysC level in the delayed focal cerebral ischemia group were higher than those in the control group without delayed focal cerebral ischemia, and CysC level in the poor prognostic outcome (GOS 1-3) group had higher CysC level than those in the group with good outcome (GOS score of 4, 5) [10].

In previous experimental studies, the mechanism of CysC on cerebral ischemia remained unclear and controversial. After suffering from focal ischemia, the size of brain infarcts was larger in CysC knockout mice than in wildtype. The mechanism was probably due to weakening the inhibition of cathepsins by CysC during brain ischemia. In contrast, after suffering from global ischemia, brain damage was diminished in CysC knockout mice, suggesting that CysC aggravates global ischemia [20]. CysC has also been shown to play an important role in atherosclerosis [16]. Higher CysC level may lead to more severe vascular wall remodeling by disrupting the balance between proteolytic and antiproteolytic activities [23]. Therefore, higher CysC level may increase the risk of DCl-related cerebral infarction by affecting the pathophysiological processes of atherosclerosis. Also, another study based on SAH animals suggested that the autophagy pathway was activated in the walls of basilar arteries after $\mathrm{SAH}$, and CysC may play a role in preventing SAH-induced cerebral vasospasm by inducing autophagy [15].

Although the results of the above clinical studies are not entirely consistent with our experimental studies, we prefer to consider the overall effects of CysC on $\mathrm{DCl}$ and need to discover more potential pathways or mechanisms by which CysC exerts an effect on $\mathrm{DCl}$. Based on previous clinical and experimental studies, CysC may have a greater effect on affecting the pathophysiological processes of atherosclerosis than preventing cerebral vasospasm after suffering aSAH.

Our study has mainly two strengths compared to previous studies. First and foremost, this study reveals the association between CysC and $\mathrm{DCl}$ after endovascular treatment of aSAH. The stability of association was confirmed with multiple methods, such as using interaction testing, generalized linear models, propensity score matching. Last but not least, different from reported studies, the length of hospitalization was taken into consideration to minimize outcome bias.

However, there are several limitations of this study. Firstly, this is a single-center retrospective study, and the reliability of the conclusion should be demonstrated in a prospective or multicenter design study. Secondly, considering a high rate of lost-to-follow-up in this retrospective study, the association between 
CysC and functional outcome (such as modified Rankin Scale and mortality) in the follow-up period was not reported in our study. Thirdly, while propensity score matching was performed to minimize unbalancing by included confounders, the effect of unmeasured confounders should not be ignored in observational studies. Lastly, the level of CysC ranges from 0.28 to $2.59 \mathrm{mg} / \mathrm{l}$ in our study, and it is unclear whether there is a saturation effect between higher CysC level and the occurrence risk of DCl.

\section{Conclusions}

CysC level could be an independent predictor for the risk of delayed cerebral ischemia after endovascular treatment of aneurysmal subarachnoid hemorrhage.

\section{Declarations}

Funding This study was supported by the Special Fund for Science and Technology of Guangdong Province (grant number: [2020]53-50), and the Dengfeng Project for the construction of high-level hospitals in Guangdong Province, The First Affiliated Hospital of Shantou University Medical College Supporting Funding.

Conflict of interest The authors declare that they have no conflict of interest.

Availability of data and material After providing a reasonable request, all supporting data for this study are available from the corresponding author.

Code availability Not applicable.

Ethical approval This study has obtained the approval from the institutional review board (grant number: B-2021-231).

Consent to participate After approval from the institutional review board, informed consent was waived in this retrospective study.

Consent for publication The consent to publish this manuscript has been received from all participants.

Authors' contributions Conception and design: Kehua Chen. Acquisition of data: Kehua Chen, Guanghua Huang, Chengwei Cai, Chuangnan Yan, Fuguang Zhang. Statistical analysis: Kehua Chen, Min Yao. Interpretation of data: Kehua Chen, Hongwu Xu. Drafting the article: Kehua Chen. Critically revising the article: Junqiang Ma, Hongwu Xu. Reviewed and approved the submitted version of manuscript: all authors.

\section{References}

[1] Chang Z, Zou H, Xie Z, et al. Cystatin C is a potential predictor of unfavorable outcomes for cerebral ischemia with intravenous tissue plasminogen activator treatment: A multicenter prospective nested 
case-control study. Eur J Neurol. 2021 ;28:1265-1274.

[2] Dengler NF, Sommerfeld J, Diesing D, Vajkoczy P, Wolf S. Prediction of cerebral infarction and patient outcome in aneurysmal subarachnoid hemorrhage: comparison of new and established radiographic, clinical and combined scores. Eur J Neurol 2018;25:111-9.

[3] Dong X, Nao J. Cystatin C as an index of acute cerebral infraction recurrence: one-year follow-up study. The International journal of neuroscience 2019;129:36-41.

[4] Dorhout Mees SM, Kerr RS, Rinkel GJE, Algra A, Molyneux AJ. Occurrence and impact of delayed cerebral ischemia after coiling and after clipping in the International Subarachnoid Aneurysm Trial (ISAT). J Neurol 2012;259:679-83.

[5] Dorhout Mees SM, Molyneux AJ, Kerr RS, Algra A, Rinkel GJE. Timing of aneurysm treatment after subarachnoid hemorrhage: relationship with delayed cerebral ischemia and poor outcome. Stroke 2012;43:2126-9.

[6] Fang YJ, Mei SH, Lu JN, et al. New risk score of the early period after spontaneous subarachnoid hemorrhage: For the prediction of delayed cerebral ischemia. CNS Neurosci Ther. 2019;25:1173-1181.

[7] Feigin VL, Lawes CMM, Bennett DA, Barker-Collo SL, Parag V. Worldwide stroke incidence and early case fatality reported in 56 population-based studies: a systematic review. The Lancet Neurology 2009;8:355-69.

[8] Frontera JA, Fernandez A, Schmidt JM, et al. Defining vasospasm after subarachnoid hemorrhage: what is the most clinically relevant definition? Stroke 2009;40:1963-8.

[9] Goertz L, Pflaeging M, Hamisch C, et al. Delayed hospital admission of patients with aneurysmal subarachnoid hemorrhage: clinical presentation, treatment strategies, and outcome. J Neurosurg 2020;134:1182-9.

[10] Goksu E, Goksu E, Karsli B, et al. Cerebrospinal fluid cystatin C levels following treatment for aneurysmal subarachnoid hemorrhage. Turk Neurosurg 2014;24:391-7.

[11] Kelly DM, Ademi Z, Doehner W, et al. Chronic Kidney Disease and Cerebrovascular Disease: Consensus and Guidance From a KDIGO Controversies Conference. Stroke. 2021;52:e328-e346.

[12] Kim JA, Rosenthal ES, Biswal S, et al. Epileptiform abnormalities predict delayed cerebral ischemia in subarachnoid hemorrhage. Clin Neurophysiol. 2017;128:1091-1099.

[13] Laterza OF, Price CP, Scott MG. Cystatin C: an improved estimator of glomerular filtration rate? Clin Chem 2002;48:699-707. 
[14] Leijenaar JF, Dorhout Mees SM, Algra A, van den Bergh WM, Rinkel GJE. Effect of magnesium treatment and glucose levels on delayed cerebral ischemia in patients with subarachnoid hemorrhage: a substudy of the Magnesium in Aneurysmal Subarachnoid Haemorrhage trial (MASH-II). International journal of stroke : official journal of the International Stroke Society 2015;10 Suppl A100:108-12.

[15] Liu Y, Cai H, Wang Z, et al. Induction of autophagy by cystatin C: a potential mechanism for prevention of cerebral vasospasm after experimental subarachnoid hemorrhage. Eur $\mathrm{J}$ Med Res 2013;18:21.

[16] Loew M, Hoffmann MM, Koenig W, Brenner H, Rothenbacher D. Genotype and plasma concentration of cystatin $\mathrm{C}$ in patients with coronary heart disease and risk for secondary cardiovascular events. Arterioscler Thromb Vasc Biol 2005;25:1470-4.

[17] Lu VM, Graffeo CS, Perry A, et al. Rebleeding drives poor outcome in aneurysmal subarachnoid hemorrhage independent of delayed cerebral ischemia: a propensity-score matched cohort study. $\mathrm{J}$ Neurosurg 2019:1-9.

[18] Maldaner N, Steinsiepe VK, Goldberg J, et al. Patterns of care for ruptured aneurysms of the middle cerebral artery: analysis of a Swiss national database (Swiss SOS). J Neurosurg. 2019; 1-10.

[19] Ni L, Lü J, Hou LB, et al. Cystatin C, associated with hemorrhagic and ischemic stroke, is a strong predictor of the risk of cardiovascular events and death in Chinese. Stroke 2007;38:3287-8.

[20] Olsson T, Nygren J, Håkansson K, et al. Gene deletion of cystatin C aggravates brain damage following focal ischemia but mitigates the neuronal injury after global ischemia in the mouse. Neuroscience 2004;128:65-71.

[21] Platz J, Güresir E, Wagner M, Seifert V, Konczalla J. Increased risk of delayed cerebral ischemia in subarachnoid hemorrhage patients with additional intracerebral hematoma. J Neurosurg 2017;126:50410.

[22] Roos YB, de Haan RJ, Beenen LF, Groen RJ, Albrecht KW, Vermeulen M. Complications and outcome in patients with aneurysmal subarachnoid haemorrhage: a prospective hospital based cohort study in the Netherlands. Journal of neurology, neurosurgery, and psychiatry 2000;68:337-41.

[23] Su M, Zhou Y, Chen Z, Pu M, Li Z, Du H, Xu G. Cystatin C predicts futile recanalization in patients with acute ischemic stroke after endovascular treatment. J Neurol. 2021

[24] Suzuki H, Shiba M, Nakatsuka Y, Nakano F, Nishikawa H. Higher Cerebrospinal Fluid pH may Contribute to the Development of Delayed Cerebral Ischemia after Aneurysmal Subarachnoid Hemorrhage. Translational stroke research 2017;8:165-73.

[25] van Gijn J, Rinkel GJ. Subarachnoid haemorrhage: diagnosis, causes and management. Brain : a journal of neurology 2001;124:249-78. 
[26] Vergouwen MDI, Vermeulen M, van Gijn J, et al. Definition of delayed cerebral ischemia after aneurysmal subarachnoid hemorrhage as an outcome event in clinical trials and observational studies: proposal of a multidisciplinary research group. Stroke 2010;41:2391-5.

[27] Wang Y, Li W, Yang J, et al. Association Between Cystatin C and the Risk of Ischemic Stroke: a Systematic Review and Meta-analysis. Journal of molecular neuroscience : MN 2019;69:444-9.

[28] Wilson TJ, Davis MC, Stetler WR, et al. Endovascular treatment for aneurysmal subarachnoid hemorrhage in the ninth decade of life and beyond. J Neurointerv Surg 2014;6:175-7.

[29] Wu Y, He Q, Wei Y, et al. The association of neutrophil-to-lymphocyte ratio and delayed cerebral ischemia in patients with aneurysmal subarachnoid hemorrhage: possible involvement of cerebral blood perfusion. Neuropsychiatr Dis Treat. 2019;15:1001-1007.

[30]Xiao D, Liu H, Zhang H, Luo Y. Impact of cystatin C levels on infarct size and hemorrhage volume in acute cerebral stroke. J Neurol 2012;259:2053-9.

\section{Figures}

\section{Figure 1}

Association between CysC and the probability of $\mathrm{DCl}$.

\section{Figure 2}

Subgroup analysis in $\mathrm{DCl}$ and the interaction test between CysC and other confounders.

\section{Figure 3}

Receiver operating characteristic analysis for predicting $\mathrm{DCl}$ by CysC level.

\section{Supplementary Files}

This is a list of supplementary files associated with this preprint. Click to download.

- STROBEchecklistcasecontrol.doc 